\title{
Internal Medicine Residents' Attitudes Toward Simulated Depressed Cardiac Patients During an Objective Structured Clinical Examination: A Randomized Study
}

\author{
Kathleen Crapanzano, MD, MACM ${ }^{7}$, Dixie Fisher, $P h D^{2}$, Rebecca Hammarlund, $P h D^{3}$, \\ Eric P. Hsieh, $M D^{4}$, and Win May, MBBS, $P h D^{2}$
}

'Department of Psychiatry, Louisiana State University Health Sciences Center, Baton Rouge, USA; '2Department of Medical Education, University of Southern California Keck School of Medicine, Los Angeles, CA, USA; ${ }^{3}$ Division of Academic Affairs, Our Lady of the Lake Hospital, Baton Rouge, LA, USA; ${ }^{4}$ Department of Internal Medicine, University of Southern California Keck School of Medicine, Los Angeles, CA, USA.

BACKGROUND: Physician biases toward mental conditions such as depression have been shown to adversely affect medical outcomes.

OBJECTIVE: To explore the relationship between residents' explicit bias toward depressed patients and their clinical skills on a cardiac case during an objective structured clinical exam (OSCE).

DESIGN: Prospective parallel randomized controlled study.

PARTICIPANTS: One hundred eighty-five internal medicine residents from three residency programs in two states.

INTERVENTION: During October-November 2015, residents were randomized to either a depressed or nondepressed standardized patient (SP) presenting with acute chest pain.

MAIN MEASURES: The Medical Condition Regard Scale (MCRS) assessed residents' explicit bias toward patients with depression. Their clinical skills (history-taking, physical examination, patient counseling, patient-physician interaction (PPI), differential diagnosis, and workup plan) and facial expressions were rated during an OSCE. KEY RESULTS: No significant relationships were found between resident explicit bias and clinical skill measurements. Residents who examined the depressed SP scored lower, on average, on history-taking $(t[183]=-2.77$, $p<0.01$, Cohen's $d=0.41)$ and higher on PPI $(t$ [183] $=$ 2.24, $p<0.05$, Cohen's $d=0.33$ ) than residents examining the non-depressed SP. There were no differences, on average, between stations on physical examination, counseling, correct diagnosis, workup plan, or overall SP satisfaction. Facial recognition software demonstrated that residents with a non-depressed SP had more neutral expressions than depressed-SP residents $(t[133]=-2.46, p<0.05$, Cohen's $d=0.46$ ), and residents with a depressed SP had more disgusted expressions than non-depressed-SP residents ( $t$ [83.52] = 2.10, $p<0.05$, Cohen's $d=0.28$ ).

CONCLUSIONS: Extrinsic bias did not predict OSCE performance in this study. Some differences were noted in the OSCE performance between the two stations. Further study is needed to examine the effects of patient mental

Received June 16, 2017

Revised October 30, 2017

Accepted December 11, 2017

Published online January 16, 2018 health conditions on physician examination procedures, diagnostic behaviors, and patient outcomes.

J Gen Intern Med 33(6):886-91

DOI: $10.1007 / \mathrm{s} 11606-017-4276-7$

(C) Society of General Internal Medicine 2018

\section{INTRODUCTION}

A prior review of literature linking depression and coronary artery disease $(\mathrm{CAD})$ found evidence of a bidirectional relationship, with depression being an independent risk factor for CAD and its complications, and CAD in turn being a cause of depression. ${ }^{1}$ Unfortunately, evidence suggests a lack of awareness of such links between mental and physical conditions among physicians. Indeed, studies have shown that physicians who attribute physical symptoms to mental conditions are less likely to investigate or treat the physical condition, ${ }^{2,3}$ especially if they are unaware of strong links between specific conditions, such as that between CAD and depression. This sort of diagnostic overshadowing is particularly likely in cases where the mental illness is complex and accompanied by communication or behavioral challenges that interfere with the clinical presentation. Diagnostic overshadowing is defined as the "process by which a person with a mental illness receives inadequate or delayed treatment because of the misattribution of their physical symptoms to their mental symptoms," ${ }^{4}$ and can lead to suboptimal care for both the mental illness and any comorbid condition.

Research has shown that, when presenting to the emergency department (ED) with chest pain, patients with depression were more likely to be triaged to a lower level and to experience a longer wait time before receiving an EKG or fibrinolysis, and were nine times as likely to miss benchmark times in receiving a balloon procedure, even with a prior history of acute myocardial infarction (AMI), than someone without a comorbid diagnosis of depression. ${ }^{5}$ Beyond the ED, people with a history of depression were more likely to be referred to low-quality surgeons ${ }^{6}$ and lower-quality hospitals ${ }^{7}$ and were less likely to receive percutaneous transluminal angioplasty or coronary artery bypass graft surgery. ${ }^{8}$ Patients with acute myocardial infarction who also had mental illness were 
marginally less likely to receive diagnostic angiography. ${ }^{9}$ Kilbourne et al. interviewed providers from high- and lowperforming sites in the Veterans Health Administration facilities and found that providers from low-performing sites reported stigma as a major concern. ${ }^{10}$ Stigmatizing attitudes on the part of healthcare providers toward mental illness influences medical outcomes in ways that are not yet fully understood. $^{9,11,12}$

Stigma among primary care providers may contribute to lower quality of care in the mentally ill population, ${ }^{13}$ and can stem from either implicit or explicit attitudes. Explicit attitudes are conscious thoughts that are associated with controlled behaviors and are influenced by social demands. Because expressions of prejudice or stereotypes associated with explicit attitudes may be modified or controlled with education, motivation, skill, and cognitive resources,${ }^{14}$ the purpose of this study was to explore the role of explicit bias in residents' diagnoses and treatment plans for a standardized patient (SP) presenting as mildly depressed, and compare their performance with residents encountering an SP without depression. Both SPs presented with acute chest pain.

The following specific research questions were addressed in this study:

1. What is the incidence and degree of internal medicine residents' extrinsic bias toward patients with depression as measured by the Medical Condition Regard Scale (MCRS)?

2. What relationships, if any, exist between residents' MCRS scores and objective structured clinical exam (OSCE) evaluation scores?

3. What differences in OSCE performance and facial expressions are observed in residents who encounter a depressed SP compared to residents who encounter a non-depressed SP?

\section{METHODS}

\section{Design}

This randomized controlled trial was conducted in October and November 2015 in two states (California and Louisiana).

\section{Recruitment}

One hundred eighty-five (112 male) internal medicine (IM) residents from three programs (a large internal medicine residency program from a large urban setting in California $[N=$ 158], and two smaller programs from Louisiana, site $1[\mathrm{~N}=$ $15]$ and site $2[N=12]$ ) were recruited and enrolled in this study. IM residents in California participated as part of their program requirements but could choose to opt out of having their data included for research; all Louisiana residents volunteered to participate. Residents from all years of training were included (postgraduate year [PGY]1 $[N=63]$, PGY2 $[N=62]$, and PGY3 $[N=60])$. Institutional review boards of Los Angeles County-USC Medical Center and LSU Health Sciences Center approved this study.

\section{Randomization}

This was a single-blinded study, with residents randomly assigned to one of two OSCE stations: 1) an SP portraying vague chest pain with no history of depression, or 2) an SP portraying vague chest pain and symptoms of depression. The same actors who portrayed the SPs were used for the encounters in both states.

\section{Intervention Process}

SPs were trained at the USC Clinical Skills Education and Evaluation Center (CSEEC) to portray a patient presenting with acute chest pain. Half of the SPs were trained on symptoms of depression as well as acute chest pain. Presentations were standardized with instructions to the depressed SPs to appear somewhat sad but to avoid mentioning their depression diagnosis or treatment unless specifically asked. After being asked, depressed SPs were instructed to more obviously express depressed symptoms or even cry during the interview. In the presenting chart of the depressed SP, a Patient Health Questionnaire (PHQ-9) score of 9 was included, versus a score of 2 included for the non-depressed SP. Scores on this instrument range from 0 to 27 , with $0-4$ indicating no to minimal depression, 5-9 mild depression, 10-14 moderate, 15-19 moderately severe, and 20-27 severe depression. Residents were given 15 min with the SP to obtain a history, perform a physical examination, and educate the SP about their diagnostic impression and treatment plan. Following each encounter, SPs completed an OSCE checklist to assess the resident (history, physical examination, and patient-physician interaction). The clinical encounter was videotaped and analyzed using facial expression recognition software (Noldus FaceReader).

After the SP interaction, residents completed a structured post-encounter note (PEN) that included their primary diagnoses (up to three) and workup plan. The PENs were scored by a physician rater based on a scoring rubric approved by the California Consortium for the Assessment of Clinical Competence (CCACC). The PENs contributed to correctness of diagnosis and workup plan scores for the OSCE. After completing their PENs, residents completed a questionnaire to measure their self-reported extrinsic bias toward depressed patients.

\section{Instruments}

Medical Condition Regard Scale (MCRS). A self-report questionnaire, the MCRS, was used to measure residents' extrinsic bias toward depressed patients. This instrument assesses "whether students find particular medical conditions to be enjoyable, treatable, and worthy of medical resources." 15 The scale consists of 11 items with six anchors ranging from 1 
(strongly disagree) to 6 (strongly agree). Scores range from 11 to 66, with higher scores representing higher regard for the condition. The instrument has shown evidence of validity in several previous studies. ${ }^{16-18}$

\section{Objective Structured Clinical Exam (OSCE) Checklist. The} SP setting has been demonstrated as a useful way to measure intervention outcomes that are sensitive or prone to social desirability biases. ${ }^{19}$ The OSCE checklist is an assessment of specific dimensions of learner performance including historytaking (17 items), physical examination (6 items), patient counseling (3 items), and patient-physician interaction (10 items), using a criterion-based proprietary checklist (developed by the CCACC), plus a global rating for SP satisfaction with the encounter. The history and physical examination portion of the checklist was based on the expert opinions of clinicians and on the Validated Clinical Decision Rule to Predict CAD as a Cause of Chest Pain. ${ }^{20}$ For the assessment of the patient-physician interaction, a modified SEGUE was used. The SEGUE framework is a research-based list of medical communication tasks and is recommended by the ACGME for the assessment of interpersonal and communication skills. ${ }^{21}$ Noldus FaceReader software ${ }^{22}$ was used to analyze facial expressions of residents during the encounter.

Post-Encounter Notes (PENs). The PEN was assessed using the rubric developed by Park et al., ${ }^{23}$ and modified by the CCACC. Differential diagnosis scores ranged from 1 to 4 , with the highest score of 4 representing all correct diagnoses (myocardial infarction/unstable angina/acute coronary syndrome) listed and correctly rank-ordered. Workup scores ranged from 1 to 4 , with the highest score of 4 requiring the inclusion of EKG, cardiac enzymes, and a reasonable workup, with few or no unnecessary tests (see Fig. 1).

\section{RESULTS}

All 186 residents were randomized to SP stations (depressed or not depressed). Four residents in the non-depressed-SP station group at California were unavailable for the OSCE at their assigned times and were reassigned to the depressed SP station. One resident did not participate in the OSCE, resulting in 97 residents in the depressed SP group and 88 residents in the non-depressed SP group.

Table 1 summarizes MCRS scores. Scores can range from 18 to 108 , with a median of 64 . Overall, scores ranged from 34 to $66(M=51.3, S D=7.2$; median $=51.0)$. Independent samples $t$ tests showed that MCRS scores did not differ significantly between SP stations, genders, or study locations, providing evidence for randomized group equivalency. Our MCRS data are congruent with what others have reported for physician attitudes toward depressed patient conditions using the instrument. ${ }^{17}$ No significant differences were noted in resident MCRS scores by gender.
With regard to our second research question, MCRS scores did not correlate significantly with any of the OSCE subscales (history-taking, physical examination, patient counseling, patient-physician interaction, correct differential diagnoses, correct workup plan, or SP satisfaction with the encounter).

Table 2 shows performance on the OSCE subscales by SP station. Independent samples $t$ tests showed that, on average, residents meeting with the depressed SP scored significantly lower on history-taking than did residents meeting with the non-depressed SP. However, on patient-physician interaction, residents meeting with the depressed SP scored significantly higher on average than residents meeting with the nondepressed SP. There were no significant differences between stations on physical exam, patient counseling, or SP satisfaction with the encounter.

Differences were found between genders on overall patient satisfaction, with the SPs reporting being more likely to return to see and/or recommend female clinicians (male $M=0.76$, $S D=0.16$; female $M=0.81, S D=0.13 ; t[183]=-2.22, p=$ 0.028). Other components of the OSCE did not differ by gender or by resident PGY.

In addition to OSCE scales, 185 residents provided PENs that included up to three differential diagnoses and a workup plan that were reviewed for correctness. Reasonable and unreasonable diagnoses and workup plans are illustrated in Figure 1. One hundred forty-seven residents (79\%) provided the correct differential diagnosis of an acute cardiac problem. Fisher's exact test (two-tailed) showed no significant difference in correctness of diagnosis by station (depressed or not depressed, $p=0.653$; Table 3). Of the 97 residents in the depressed SP station, 36 (37\%) included depression as one of their differential diagnoses; eight $(8.7 \%)$ of these residents wrongly listed depression as the top differential diagnosis.

Workup plans showed that $68 \%$ of residents in the depressed station selected the correct workup plan (score of 3 or 4) versus $76 \%$ of residents in the non-depressed station. Thirty-two percent of residents in the depressed station and $24 \%$ in the non-depressed station chose only EKG or cardiac enzymes for their workup. There was no significant difference between the two stations on the residents' workup plans (Table 4).

The occurrence of specific facial expressions along with overall affective valence during patient interactions was analyzed using facial expression recognition software. Forty-five of the participants had no readable video to analyze, while six were analyzed but provided insufficient data; thus, the sample was reduced to 134 for these analyses. Stations did not differ on happy, sad, angry, surprised, or scared expressions, nor on overall valence. Non-depressed-SP residents $(M=0.28, S D=$ $0.10)$ had more neutral expressions than depressed-SP residents $(M=0.24, S D=0.07, t[133]=-2.46, p<0.05$, Cohen's $d=0.46)$, and depressed-SP residents $(M=0.02, S D=0.05)$ had more disgust expressions than non-depressed-SP residents $(M=0.01, S D=0.01, t[83.52]=2.10, p<0.05$, Cohen's $d=$ 0.28 ), but these differences were not significant at a 


\begin{tabular}{|l|l|}
\hline Score & \multicolumn{1}{|c|}{ DIAGNOSTIC ACCURACY } \\
\hline 4 Points & $\begin{array}{l}\text { All three differentials are reasonable diagnoses, and the top differential must include one of the } \\
\text { acceptable correct answers (MI/UA/ACS) }\end{array}$ \\
\hline 3 Points & $\begin{array}{l}\text { All three differentials are reasonable diagnoses, and the second or third differential includes one of the } \\
\text { acceptable correct answers (MI/UA/ACS) }\end{array}$ \\
\hline 2 Points & $\begin{array}{l}\text { Two of the three differentials include two reasonable diagnoses, with one of them being an acceptable } \\
\text { correct answer (MI/UA/ACS) }\end{array}$ \\
\hline 1 Point & Correct diagnoses (MI/UA/ACS) not listed in the differential \\
\hline $\begin{array}{l}\text { Note: Depression was accepted in the depressed SP station as a reasonable diagnosis, but if it was listed first, resident's score was down-graded. } \\
\text { Acceptable/Correct diagnostic answers: Myocardial Infarction (MI), Unstable Angina (UA), Acute Coronary Syndrome (ACS). } \\
\text { Valid answers, but would not get top score: Angina, Stable angina, GERD, Aortic dissection, Pulmonary embolism. } \\
\text { Unreasonable answers: Atypical Chest Pain, Hypertension, Aortic Stenosis, Pericarditis, Arrhythmia, Costochondritis, Esophageal Spasm, Gastritis, } \\
\text { Cancer }\end{array}$ & \multicolumn{1}{|c|}{ WORKUP PLAN ACCURACY } \\
\hline Score & $\begin{array}{l}\text { Effective and efficient plan for diagnostic workup, includes EKG and cardiac enzymes. Has few or no } \\
\text { unnecessary tests }\end{array}$ \\
\hline 4 Points & $\begin{array}{l}\text { Reasonable plan for diagnostic workup, includes EKG and cardiac enzymes. May have some unnecessary } \\
\text { tests }\end{array}$ \\
\hline 3 Points & $\begin{array}{l}\text { Ineffective plan with most essential tests missed (EKD and cardiac enzymes), AND/OR inefficient plan } \\
\text { with many irrelevant tests included }\end{array}$ \\
\hline 2 Points & Diagnostic workup ordered or omitted would place patient in unnecessary risk or danger \\
\hline 1 Point &
\end{tabular}

Figure 1 Post-encounter note scoring rubric.

Bonferroni-corrected alpha value of 0.006. PGY groups did not differ on specific facial expressions or overall valence, nor did specific expressions or overall valence correlate with OSCE or MCRS scores. However, differences were noted by gender on the facial affect measurements. Male and female residents differed on sad, angry, scared, and overall valence. Male residents were more likely to demonstrate an angry affect (males 0.07 [0.07] vs. females 0.04 [0.05], $t$ [131.57] = 3.60, $p<0.001)$. Female residents were more likely to demonstrate a sad (males 0.09 [0.07] vs. females 0.17 [0.09], $t$ [92.27]= $-5.48, p<0.00$ ) or scared affect (males 0.01 [0.02] vs. females $0.02[0.04], t[65.08]=-2.13, p=0.015)$. When looking at the overall valence of the affect, male residents had an overall more positive affect than female residents (males 0.05 [0.12] vs. females $-0.01[0.14], t[133]=2.64, p=0.009)$.

\section{DISCUSSION}

In this study, we explored the incidence and degree of extrinsic bias among internal medicine residents toward patients with depression as measured by the MCRS, and we correlated residents' MCRS scores with their scores from an acute cardiac case OSCE. We predicted that resident physicians who explicitly endorsed negative biases against individuals with depression on the MCRS would not perform as well during the OSCE if the SP presented with comorbid depression. While we did find that the MCRS reflected overall low regard for patients with depression in our sample, our results are actually more positive than the results from the original study that validated the scale. Our results did not support the hypothesis that this low regard was related to OSCE performance. One possible explanation for this null finding is that residents can and do suppress their conscious biases while examining and treating patients. Although we did not collect any data that could speak directly to this possibility, explicit biases are, by virtue of being explicit, under conscious control and therefore susceptible to willful concealment or modification. ${ }^{24}$ With regard to our final research question, SP stations did differ on two OSCE subscales. Average scores of residents in the depressed SP station were lower on the history-taking component and higher on the patient-physician interaction component of the OSCE than were scores of residents in the nondepressed-SP station. However, these effects were not large (i.e., Cohen's $d$ values between 0.33 and 0.41 ). Residents who encountered the depressed SP may have taken more time to speak with the SP about her depression, resulting in some of the "history-taking" checklist items being missed. It was interesting to find residents in the depressed SP station scoring higher, on average, on patient-physician interaction than residents in the non-depressed-SP station. The patient-physician interaction portion of the OSCE is a 10-item checklist measuring rapport, empathy, and communication skills. Residents who met with the depressed SP were perceived to have more of these qualities than residents who met with the nondepressed patient.

When reviewing the PENs, our results showed that $79 \%$ of residents from both the depressed and non-depressed stations provided the correct differential for an acute cardiac problem. In our study, there was also no significant difference between stations in workup plans submitted by the residents $(68 \%$ of

Table 1 MCRS Mean Scores (Extrinsic Bias Toward Depressed Patients)* by OSCE Station, Gender, and Study Location

\begin{tabular}{|c|c|c|c|c|}
\hline Variable & Descriptor & No. (\%) & $\begin{array}{l}\text { Mean } \\
(S D)\end{array}$ & Significance \\
\hline $\begin{array}{l}\text { OSCE } \\
\text { station }\end{array}$ & $\begin{array}{l}\text { Depressed } \\
\text { Not } \\
\text { depressed }\end{array}$ & $\begin{array}{l}97 \\
(52 \%) \\
88 \\
(48 \%)\end{array}$ & $\begin{array}{l}51.77 \\
(7.61) \\
50.72 \\
(6.710)\end{array}$ & NS \\
\hline Gender & $\begin{array}{l}\text { Male } \\
\text { Female }\end{array}$ & $\begin{array}{l}112 \\
(61 \%) \\
73 \\
(39 \%)\end{array}$ & $\begin{array}{l}50.95 \\
(7.50) \\
51.76 \\
(6.75)\end{array}$ & NS \\
\hline Study site & $\begin{array}{l}\text { CA program } \\
\text { LA } \\
\text { programs }\end{array}$ & $\begin{array}{l}158 \\
(85 \%) \\
27 \\
(15 \%)\end{array}$ & $\begin{array}{l}51.56 \\
(7.08) \\
49.56 \\
(7.79)\end{array}$ & NS \\
\hline
\end{tabular}

*Higher scores reflect higher regard for the patient 
Table 2 Comparison of Resident Performance by Station Assignment (Depressed SP vs. Non-Depressed SP) on Five OSCE Components in an Acute Cardiac Case

\begin{tabular}{|c|c|c|c|}
\hline \multirow[t]{2}{*}{ Variable } & \multirow{2}{*}{$\begin{array}{l}\text { Depressed } \\
\text { SP station } \\
N=97 \\
\text { Mean } \\
(S D)\end{array}$} & $\begin{array}{l}\text { Non- } \\
\text { depressed } \\
\text { SP station } \\
N=88\end{array}$ & \multirow[t]{2}{*}{ Significance } \\
\hline & & Mean $(S D)$ & \\
\hline History & $\begin{array}{l}11.97 \\
(2.01)\end{array}$ & $\begin{array}{l}12.80 \\
(2.05)\end{array}$ & $\begin{array}{l}t(183)=-2.77, p= \\
0.006, \text { Cohen's } d= \\
0.41\end{array}$ \\
\hline Physical exam & $2.18(1.14)$ & $2.11(1.23)$ & $\mathrm{NS}$ \\
\hline $\begin{array}{l}\text { Patient } \\
\text { counseling }\end{array}$ & $2.49(0.81)$ & $2.49(0.83)$ & NS \\
\hline $\begin{array}{l}\text { Patient- } \\
\text { physician } \\
\text { interaction }\end{array}$ & $7.97(1.73)$ & $7.36(2.09)$ & $\begin{array}{l}t(183)=2.24, p= \\
0.027, \text { Cohen's } d= \\
0.33\end{array}$ \\
\hline $\begin{array}{l}\text { SP satisfaction } \\
\text { with encounter }\end{array}$ & $0.80(0.15)$ & $0.77(0.16)$ & NS \\
\hline
\end{tabular}

residents in the depressed station selected the correct workup plan vs. $76 \%$ of residents in the non-depressed station). This is different from studies in real-life situations, where patients with a charted history of depression received a lower-priority triage score than did those without a documented history of depression. ${ }^{5}$ It may be that residents in our testing situation chose the correct workup plan, as AMI has been taught as a "rule-out" diagnosis in acute chest pain. Alternatively, awareness of the simulated patient encounter and the nature of the encounter as an assessment of resident skills may have made the residents more acutely aware of their decision-making, and that awareness may have helped them overcome any potential cognitive bias.

The differences in facial expressions of residents when working with the depressed patients (more occurrences of the disgust affect) versus non-depressed patients (more occurrences of a neutral affect) were small but interesting. These could be explained by differences in the content of the discussion between the resident and patient or perhaps by an unconscious bias of which the resident was unaware. The differences noted in the facial expressions of residents by gender might represent a mirroring of the patients' expressions by the female residents, a manifestation of empathy, ${ }^{25}$ and could help
Table 4 Workup Plan by OSCE Station (Depressed SP vs. NonDepressed SP)

\begin{tabular}{|c|c|c|c|c|c|}
\hline \multirow[t]{2}{*}{ Score } & \multirow[t]{2}{*}{ Workup } & & \multicolumn{2}{|c|}{ OSCE station } & \multirow[t]{2}{*}{ Total } \\
\hline & & & Depressed & $\begin{array}{l}\text { Not } \\
\text { depressed }\end{array}$ & \\
\hline 1 & $\begin{array}{l}\text { No } \\
\text { mention of } \\
\text { EKG or } \\
\text { cardiac } \\
\text { enzymes }\end{array}$ & $\begin{array}{l}\text { Count } \\
\% \\
\text { within } \\
\text { OSCE } \\
\text { station }\end{array}$ & $\begin{array}{l}0 \mathrm{a} \\
0.0 \%\end{array}$ & $\begin{array}{l}0 \mathrm{a} \\
0.0 \%\end{array}$ & $\begin{array}{l}0 \\
0.0 \%\end{array}$ \\
\hline 2 & $\begin{array}{l}\text { EKG or } \\
\text { cardiac } \\
\text { enzymes }\end{array}$ & $\begin{array}{l}\text { Count } \\
\% \\
\text { within } \\
\text { OSCE } \\
\text { station }\end{array}$ & $\begin{array}{l}31_{\mathrm{a}} \\
59.6 \%\end{array}$ & $\begin{array}{l}21_{\mathrm{a}} \\
40.4 \%\end{array}$ & $\begin{array}{l}52 \\
100.0 \%\end{array}$ \\
\hline 3 & $\begin{array}{l}\text { EKG and } \\
\text { cardiac } \\
\text { enzymes } \\
\text { but no } \\
\text { additional } \\
\text { workup }\end{array}$ & $\begin{array}{l}\text { Count } \\
\% \\
\text { within } \\
\text { OSCE } \\
\text { station }\end{array}$ & $\begin{array}{l}26_{\mathrm{a}} \\
51.0 \%\end{array}$ & $\begin{array}{l}25 \mathrm{a} \\
49.0 \%\end{array}$ & $\begin{array}{l}51 \\
100.0 \%\end{array}$ \\
\hline \multirow[t]{3}{*}{4} & $\begin{array}{l}\text { EKG, } \\
\text { cardiac } \\
\text { enzymes, } \\
\text { plus } \\
\text { reasonable } \\
\text { workup }\end{array}$ & $\begin{array}{l}\text { Count } \\
\% \\
\text { within } \\
\text { OSCE } \\
\text { station }\end{array}$ & $\begin{array}{l}400_{\mathrm{a}} \\
48.8 \%\end{array}$ & $\begin{array}{l}42 \mathrm{a} \\
51.2 \%\end{array}$ & $\begin{array}{l}82 \\
100.0 \%\end{array}$ \\
\hline & & $\begin{array}{l}\text { Total } \\
\text { count }\end{array}$ & 97 & 88 & 185 \\
\hline & & $\begin{array}{l}\text { Total } \\
\%\end{array}$ & $52.4 \%$ & $47.6 \%$ & $100.0 \%$ \\
\hline
\end{tabular}

Results of comparisons between column counts/proportions are shown using subscripts (a). Proportions with the same subscript are not significantly different, while proportions with different subscripts are significantly different from one another at $p \leq 0.05$

explain the increased likelihood of patient satisfaction with the encounter when the clinician was female.

In terms of limitations, the most obvious is the artificiality of the situation. Although previous research has suggested that the OSCE is appropriate for testing interventions susceptible to social desirability bias, ${ }^{19}$ we cannot rule out the possibility that residents may have adopted an apprehensive participant role during the study, thus altering their behavior so as to appear unbiased against those with mental health issues. In support of the idea that demand characteristics may have influenced residents' behaviors, the encounter videos showed that SP depression behaviors were frequently exaggerated (i.e., crying) relative to the diagnosis of mild depression found

Table 3 Diagnosis by OSCE Station (Depressed SP vs. Non-Depressed SP)

\begin{tabular}{|c|c|c|c|c|c|}
\hline \multirow[t]{2}{*}{ Score } & \multirow[t]{2}{*}{ Differential diagnosis (DDX) } & & \multicolumn{2}{|c|}{ OSCE station } & \multirow[t]{2}{*}{ Total } \\
\hline & & & Depressed & Not depressed & \\
\hline 1 & DDX no mention of AMI/UA/ACS & $\begin{array}{l}\text { Count } \\
\% \text { within OSCE station }\end{array}$ & $\begin{array}{l}21_{\mathrm{a}} \\
21.6 \%\end{array}$ & $\begin{array}{l}17 \mathrm{a} \\
19.3 \%\end{array}$ & $\begin{array}{l}38 \\
20.5 \%\end{array}$ \\
\hline \multirow[t]{2}{*}{$2-4$} & $\begin{array}{l}2=\text { reasonable DDX including } \mathrm{AMI} / \mathrm{UA} / \mathrm{ACS} \\
3=\text { all } 3 \text { reasonable DDX AMI/UA/ACS not first, } \\
4=\text { all } 3 \text { reasol first }\end{array}$ & $\begin{array}{l}\text { Count } \\
\% \text { within OSCE station }\end{array}$ & $\begin{array}{l}76 \mathrm{a} \\
78.4 \%\end{array}$ & $\begin{array}{l}71_{\mathrm{a}} \\
80.7 \%\end{array}$ & $\begin{array}{l}147 \\
79.5 \%\end{array}$ \\
\hline & & $\begin{array}{l}\text { Total count } \\
\text { Total \% }\end{array}$ & $\begin{array}{l}97 \\
100.0 \%\end{array}$ & $\begin{array}{l}88 \\
100.0 \%\end{array}$ & $\begin{array}{l}185 \\
100.0 \%\end{array}$ \\
\hline
\end{tabular}

Results of comparisons between column counts and proportions are shown using subscripts (a). Proportions with the same subscript are not significantly different, while proportions with different subscripts are significantly different from one another at $p \leq 0.05$

AMI acute myocardial infarction, UA unstable angina, ACS acute coronary syndrome 
in their chart. The increased salience of depressive symptoms may have been a cue to residents as to the purpose of the study. Although all participants volunteered for the study, the OSCE was a requirement of the residency program at one site, and optional at the other site.

In summary, our study revealed differences in the evaluation and care of a person with depression and cardiac illness. However, there was no correlation with explicit bias. Additional studies with even larger groups are needed to examine the effects of physician attitudes and behaviors on the care of people with comorbid physical and mental health conditions, to understand the factors that impact clinical outcomes for this population.

Acknowledgements: This project was supported by funding from the Association of American Medical Colleges (AAMC) Southern Group on Educational Affairs and the Western Group on Educational Affairs. The authors thank them both for their support.

Corresponding Author: Kathleen Crapanzano, MD, MACM; Department of PsychiatryLouisiana State University Health Sciences Center, Baton Rouge, USA (e-mail: Kcrap1@lsuhsc.edu).

\section{Compliance with Ethical Standards:}

Conflict of Interest: The authors declare that they do not have a conflict of interest.

\section{REFERENCES}

1. Khawaja IS, Westermeyer JJ, Gajwani P, et al. Depression and coronary artery disease: the association, mechanisms, and therapeutic implications. Psychiatry (Edgmont). 2009;6(1):38-51.

2. Jones S, Howard L, Thornicroft G. Diagnostic overshadowing: worse physical health care for people with mental illness. Acta Psychiatrica Scandinavica. 2008; 118(3):169-71

3. Merrick J, Merrick E. Equal Treatment: Closing the Gap. A Formal Investigation into Physical Health Inequalities Experienced by People with Learning Disabilities and/or Mental Health Problems. J Policy Pract Intellect Disabil. 2007;4(1):73.

4. Shefer G, Henderson C, Howard LM, et al. Diagnostic overshadowing and other challenges involved in the diagnostic process of patients with mental illness who present in emergency departments with physical symptoms-a qualitative study. PLoS One. 2014;9(11):e111682.

5. Atzema CL, Schull MJ, Tu JV. The effect of a charted history of depression on emergency department triage and outcomes in patients with acute myocardial infarction. CMAJ. 2011;183(6):663-9.

6. Li Y, Glance LG, Cai $\mathbf{X}$, et al. Are patients with coexisting mental disorders more likely to receive CABG surgery from low-quality cardiac surgeons? The experience in New York State. Med Care. 2007;45(7):58793.

7. Cai X, Li Y. Are AMI patients with comorbid mental illness more likely to be admitted to hospitals with lower quality of AMI care? PLoS One. 2013;8(4):e60258.

8. Druss BG, Bradford DW, Rosenheck RA, et al. Mental disorders and use of cardiovascular procedures after myocardial infarction. JAMA. 2000;283(4):506-11.

9. Petersen LA, Normand S-LT, Druss BG, et al. Process of Care and Outcome after Acute Myocardial Infarction for Patients with Mental Illness in the VA Health Care System: Are There Disparities? Health Serv Res. 2003;38(1 Pt 1):41-63.

10. Kilbourne AM, Greenwald DE, Bauer MS, et al. Mental health provider perspectives regarding integrated medical care for patients with serious mental illness. Adm Policy Ment Health. 2012;39(6):448-57.

11. Leucht S, Burkard T, Henderson $\mathbf{J}$, et al. Physical illness and schizophrenia: a review of the literature. Acta Psychiatrica Scandinavica. 2007; 116(5):317-33.

12. Schulman KA, Berlin JA, Harless W, et al. The Effect of Race and Sex on Physicians' Recommendations for Cardiac Catheterization. N Engl J Med. 1999;340(8):618-26.

13. Thornicroft G. Premature death among people with mental illness. BMJ; 2013;346:f2969.

14. Monteith LL, Pettit JW. Implicit and Explicit Stigmatizing Attitudes and Stereotypes About Depression. J Soc Clin Psychol. 2011;30(5):484-505.

15. Ward TD. Do you hear what I hear? the impact of a hearing voices simulation on affective domain attributes in nursing students. Nurs Educ Perspect. 2015;36(5):329-31.

16. Christison G, Haviland M, Riggs $\mathbf{M}$. The medical condition regard scale: measuring reactions to diagnoses. Acad Med. 2002;77(3):257-62.

17. Gilchrist G, Moskalewicz J, Slezakova S, et al. Staff regard towards working with substance users: a European multi-centre study. Addiction. 2011;106(6):1114-25.

18. Williams B, Brown T, Boyle M, et al. The Medical Condition Regard Scale (MCRS): An examination of its factor structure using paramedic students. Nurse Educ Today. 2013;33(9):938-43.

19. Li L, Lin C, Guan J. Using standardized patients to evaluate hospitalbased intervention outcomes. Int J Epidemiol. 2014;43(3):897-903.

20. McConaghy JR, Oza RS. Outpatient diagnosis of acute chest pain in adults. Am Fam Physician. 2013;87(3):177-82.

21. Hobgood CD, Riviello RJ, Jouriles N, et al. Assessment of Communication and Interpersonal Skills Competencies. Acad Emerg Med. 2002;9(11):1257-69.

22. Benta K, Van Kuilenburg H, Eligio, UX, et al. (2009). Evaluation of a system for real-time valence assessment of spontaneous facial expressions. Distributed Environments Adaptability, Semantics and Security Issues, International Romanian - French Workshop, Cluj-Napoca, Romania, September, 17-18, 2009.

23. Park YS, Lineberry M, Hyderi A, et al. Validity evidence for a patient note scoring rubric based on the new patient note format of the United States Medical Licensing Examination. Acad Med. 2013;88(10):1552-7.

24. Plant EA, Devine PG. Internal and external motivation to respond without prejudice. J Pers Soc Psychol. 1998; 7593: 811-32.

25. Hojat M, DeSantis J, Gonnella JS. Patient perceptions of clinician's empathy: measurement and psychometrics. J Patient Exp. 2017;4(2):7883. https://doi.org/10.1177/2374373517699273. 